\title{
Youth using national symbols in constructing identities
}

\author{
Layal Kasselias Wiltgren
}

\section{Linköping University Post Print}

\section{Tweet}

N.B.: When citing this work, cite the original article.

This is an electronic version of an article published in:

Layal Kasselias Wiltgren, Youth using national symbols in constructing identities, 2014, Journal of Youth Studies, (17), 3, 308-323.

http://dx.doi.org/10.1080/13676261.2013.815706

Copyright: Taylor \& Francis (Routledge): SSH Titles

http://www.routledge.com/

Postprint available at: Linköping University Electronic Press

http://urn.kb.se/resolve?urn=urn:nbn:se:liu:diva-104149 
Youth using national symbols in constructing identities 


\begin{abstract}
Artefacts containing national or ethnic symbols, such as flags and maps, are frequently used by 14 year old youth in a multiethnic, suburban municipality in Stockholm. Appearing as ornaments or trinkets to outsiders, to the initiated they are distinctive group markers displaying multiple political and ideological affiliations. As visual symbols these artefacts invoke communicative, but non-verbal, processes: they interpellate viewers who answer with their reactions. Thus these objects serve to both banally reproduce nationalism and ethnicity, and to serve as identity markers. These identities are primarily inclusive and nonaggressive. The symbols do not seem to be a sign of resistance to mainstream Swedish society in line with much work in the field of youth culture. Instead, they are used as a proud, visual display of additional identities complementing the Swedish one. Ethnicity research often covers linguistic markers or ethnic and national identities. In contrast, the area of youth consumption of nationalism, in the form of objects featuring national, ethnic and religious symbols, is as yet not well documented. Based on a year-long fieldwork in a junior high school, this paper documents ways in which minority group students handle material artefacts and what these symbols involved mean to them.
\end{abstract}

Keywords: National symbols; identity; minority groups; ethnicity; youth culture 
National identity is not an innate quality in human being. Like other aspects of identity it has to be learnt. Benedict Anderson (1983/2003) defines a 'nation' as 'an imagined political-community and imagined as both inherently limited and sovereign'. It is imagined because the members of even the smallest nation will never know, meet or even hear of most of their fellow-members, yet in the mind of each lives the image of their communion (Anderson, 1983/2003: 5-6). In fact, all communities larger than primordial villages, where face-to-face contact with every member is possible, are imagined. Despite the fact that nations are imagined political communities, Anderson emphasizes that people may have deep and intense feelings for their nation and that many are willing to die for it.

In this view, ethnic and national identities are constructions. They are neither fixed nor naturally given (Eriksen, 1993/2007: 127) and are expressed primarily in interaction with others. Despite the fact that nations are modern creations their mythology gives the impression that they have always existed (Billig, 1995/2004: 29). Nations, like other group identities, are negatively defined, that is, by what they are not, and always in relation to those not included; nations cannot exist in isolation (Eriksen, 1993/2007: 42).

According to Billig (1995/2004: 22), nationalism is to be seen as the most successful ideology in human history; it is a global ideology. In both popular and academic writing, nationalism is associated with those who struggle to create new territorial states 
or with extreme right-wing politics. At the same time, nationalism is defined as something dangerously emotional and irrational, as a problem, but with the irrationality of nationalism projected on the other (Billig, 1995/2004: 38). It is often seen as an exotic force operating on the periphery and people in established nations are led to see nationalism as the property of others, while in fact nations are daily reproduced, in a banal, mundane way, through a complex web of beliefs, assumptions, habits, representations and practices (Billig, 1995/2004:6). In the nations of the Western world it is taken for granted, it ceases to appear as nationalism, disappearing into the natural environment of societies. Despite the fact that we don't reflect upon it, nationalism does exist all around us. The reproduction of a nation does not occur magically. Banal practices, rather than conscious choice or collective acts of imagination, keep nations alive (Billig, 1995/2004: 95) and there is a continual 'flagging' or reminding of nationhood. In ever so many tiny, almost insignificant ways, the citizenry is daily reminded of their national place in a world of nations. Such reminders are so familiar, so continuous that they are not consciously registered as reminding (Billig, 1995/2004: 8). The point made by Billig takes attention away from the spectacular and places the focus on the impact of national symbols constantly flagged in our everyday lives.

Jenkins argues, however, that describing nationalism as banal might be misleading and does not help us to understand the relationship between taken-for-grantedness and emotional power. Commonplace does not mean banal and the fact that a symbol is 
commonplace says nothing about the relationship individuals have with national symbols (Jenkins, 2007: 116). Jenkins (2007:129) therefore insists that we need to look at how the taken-for-granted, background presence of a flag might be anything but banal in the emotional sense. We need a better term than banal to conceptualize this.

Miller-Idriss and Rothenberg (2012) argue that most academic work on nationhood and national identity focus on the state and how its elite members construct nations. While these studies shed light on the ways in which the nation-state and its elites have made national world-views publically available for its citizens, they have largely overlooked the place of the individual in validating or integrating such world-view. Eric Hobsbawm (1991:10) points out that while nationalism is constructed essentially from above, it cannot be understood unless also analysed from below, that is in 'terms of the assumptions, hopes, needs, longings and interests of ordinary people, which are not necessarily national and still less nationalist'.

Billig argues that the study of nationalism should relate to the everyday way of life and yet his study, which is considered one of the most influential studies addressing nationalism, does not problematize the fact that individuals themselves reproduce nations by 'banal' acts (Skey, 2009: 337) such as visual artefacts. The area of young people reproducing nations by the use of symbols is even less explored.

\section{Visual symbols}


Visual images are representations: an image of a chair is not a chair; one cannot feel it nor sit on it. The image carries meanings that have to be interpreted in order to be understood (Hall, 1997: 19). Symbols are the cultural ciphers through which meanings are assigned to phenomena and attachments made between people and things (Geertz, 1973: 216).

Objects and images are not static entities (Sturken and Cartwright, 2009: 3). They are active agents in that they make us look, feel or talk in specific ways. It is by our use of things, by what we say, think and feel about them, and how we represent them, that we fill them with meaning (Hall, 1997:3). Meaning is not inherent in things, or in the world, it is constructed and produced: 'It is the result of a signifying practice. A practice that produces meaning, that makes things mean' (Hall, 1997: 24). Thus an image is created at the moment it is consumed and may change through negotiations amongst viewers (Sturken and Cartwright, 2009:49). Symbols are not required to be consistent (Jenkins, 2007:116). They are abstract, often arbitrary, and individuals are able to come together under the collective spell of their enchantment without having to explore their individual difference from each other. Symbols allow people to imagine that they have something in common despite the many things that divide them, and as a result, of course, they do have - or will come to have - something in common (Jenkins, 2007). 
The philosopher Louis Althusser emphasizes the importance of hailing and response. In a classic example, a police hails a man in the street: 'Hey, you there!' As the hailed individual turns around he becomes a subject in an ideology - a process called interpellation (Althusser, 1971/2001: 118). The term adapted by political and media theorists in the 1970s, made the case that images interpellate viewers. Images seem to call out to us, catching our attention (Sturken and Cartwright, 2009: 50). Symbols are multivocal and multivalent: they mean different things to different people at different times (Fox and Miller-Idriss 2008).

\section{Fieldwork}

While all agree that nations are social constructs, few have operationalized empirically the ways in which ordinary people participate in such national constructions. Fox and Miller-Idriss (2008: 556) advocate a 'wait-and-listen' approach in order to see how and when nationhood comes up in the interactional context of everyday life and that participant observation is best suited for this sort of investigation.

The empirical data are taken from a yearlong ethnographic study with extensive audiorecordings (more than 300 hours) and participant observations, following two eighth grade classes in a multi-ethnic school on the outskirts of Stockholm. The area was chosen due to the high proportion of varying ethnic backgrounds, as the aim of the overall research project was to study ethnicity as a multidimensional resource. The 
analysis focuses on the local level and on the way the students exhibit great creativity in combining multiple semiotic resources, creating aspects of their ethnicity and nationalism, location and culture. Special attention is paid to how these signifiers are comprehended, given form and communicated in everyday intrapersonal interactions. The study draws on an aspiration to uncover emic perspectives (cf. Eriksen, 2010: 40) and the analyses are based on recorded interactions of naturally occurring conversations, participant observations and interview material.

Almost all the students in the school are minority group students, first or second generation immigrants from Turkey, Iraq and other countries in the Middle East. Some of the teachers also have Middle East background and are bilingual speakers of Turkish, Arabic and Swedish. The author has grown up in Sweden (since the age of eight years) but has a Syrian background and is a bilingual speaker of Arabic and Swedish. This fact facilitated access to the field, as it was seen as an advantage by the school management, the students themselves, and their parents.

All students, parents and teachers were given detailed information on the purpose of the study, their anonymity in it and that participation was voluntary and could be interrupted at any time. 
Most conversations took place in Swedish, including codeswitching to other languages. In the translation process, care has been taken to stick relatively close to the original conversations in order to retain a sense of the participant's own use of language.

\section{It's all about love: national representation and love}

Personal artefacts, ranging from cheap key chains to gold pendants and clothes, featuring maps and flags appear frequently in the school where I did my fieldwork. The maps and flags spanned a large variety of nations, with the Iraqi and Kurdish ones being the most frequent. Flags were also often drawn on notebooks, files and folders next to the students' own names. These artefacts were important personal belongings, partly because they had a strong emotional value and partly because, at the time of my fieldwork, they were hard to obtain in Sweden. They could not be bought at the convenience store, and were often specially ordered from abroad. At one point, Diana, one of the students in the study, tells me and her friends that she had to 'go to war' in order to obtain the gold pendant she now constantly wears, one featuring the Iraqi map with an inset Christian cross (Figure 1): 'Yeah, I really wanted it. I had to nag my parents so damn much before they bought it for me'. Miles et al. state that young people have budgets within which they must operate. The decision to purchase is therefore a well thought out and planned one which weights up practical issues and consumer preferences. However, far from use value playing a dominant role, the symbolic use of 
goods is clearly important. Consumption also gives pleasure to young people when it involves elements of display and negotiation (Miles et al. 1998).

I had been in school merely a few days when Zahra informs

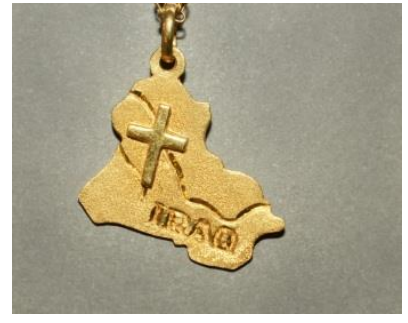

Figure 1 me that she wishes to print the Iraqi flag on her right sleeve. She taps her arm lightly to show exactly where she wants the flag to be and how big she wants it to be. She then explains:

Zahra: I want! I like! I love Iraq!

Layal: What do you love about Iraq?

Zahra: I don't know [shrugs].

Layal: When were you last there?

Zahra: I've never been there.

Layal: How can you love it then? [Slightly baffled]

Zahra: 'Cause that's where I come from, or rather that's where my parents come from.

Layal: But how can you love a place you've never been to?

Zahra: I love the people.

Zahra has never been to Iraq. Neither has she met any Iraqis who still live in Iraq. When Zahra talks about Iraq she then partly talks about an imagined community (Anderson 
1983/2003). But while her fellowship with people she has never seen and places she has never visited is imagined, there is no mistaking about the love Zahra feels for them.

'I want so very much!' she says longingly about the printed flag, and continues:

'my mother asks why, I say I want the whole world to know that I am from Iraq.'

Together with her friends who share her Iraqi background, Zahra frequently talks about national symbols. They plan to print shirts with a large map of Iraq on the back and a small Iraqi flag on the front, on the left, over the heart. Beneath the flag they want to print their own names. Zahra says that it would be even better if they could have a brand name shirt such as Adidas(TM). The value of the shirts is both utility-driven and symbolically-driven.

Meanwhile Diana makes woven bracelets in the colours of the Iraqi flag. In the middle of the bracelet, on the white part, Diana writes her own name. On seeing the bracelet, Zahra craves one of her own and Diana makes one for her.

The girls strive to be part of a national project through the map and the flag, to be an individual through their own names and to be a consumerist in a consumer's society through the German-based brand Adidas(TM). These are three ideologies working alongside; a combination of national symbols, consumption and handcraft. Fox and Miller-Idriss (2008) emphasize that ordinary people are not simply uncritical consumers 
of the nation; they are simultaneously its creative producers through everyday acts of consumption (cf. Billig 1995/2004). Individuals position themselves stylistically and are interpreted by others as they present themselves within a given social context as specific kinds of people who engage in particular social practices (Bucholtz 2011).

Customizing and personalizing their shirts shows that the shirts are theirs and not borrowed. Nor are they purchased over the counter in one of the district's many clothing stores, but they are custom made by the girls. For those unfamiliar with the girls, the shirts signal what they are. Thus the shirts show group affiliation, while also revealing uniqueness.

Displaying affiliations through appearance is a common strategy; usually distinguishable, and always visible. Widdicombe and Wooffitt (1995) have analysed youth subcultural identities among punks and goths with visible attributes, that is, groups who are often seen as rebellious by mainstream society. When asked to describe themselves some respondents, resisting labels, answered that they were simply human beings. This challenges the assumption that there is a unitary meaning of subcultures (Widdicombe and Wooffitt, 1995). Contrary to a common belief, the social practices of youth are nor designed or deployed primarily to rebel against adults but to identify with and distinguish themselves from their peers (Bucholtz 2011:12). I use the view of identity as a discursive accomplishment, a matter of 'doing' rather than simply 'being'. 
It is important to emphasize that the youth of course are not only Iraqis or Kurds, either in their own or others imagination. They are not walking billboards of national symbols (cf. Ackroys and Pilkington, 1999, Hart, 2002); that they may appear this way says more about this study's area of focus than about the students themselves. Ethnicity is only part of who they are. They take and convey a multitude of other positions related to identities, such as gender, age, class, ethnicity and fashion (cf. Yuval-Davis, 2006). Some students wear clothes associated with football teams such as Italian AC Milan or Spanish Real Madrid. In Diana's bedroom a large Iraqi flag hangs next to an equally large poster of U.S. pop singer Britney Spears. It is also important to remember that the group affiliations are not static, but rather under constant negotiation (Schmitt, 2010: 175).

When I ask the students why they want to wear their national symbols, they answer without hesitation: 'To show that we are proud!' Diana replies. 'Why else?' she adds, looking askance at me, as if the answer is obvious. Diana's rhetorical question makes me feel a bit foolish for asking in the first place. It is a feeling I often get when asking questions - that I should know that the answers are obvious. 'We want to show that we are proud, but I feel it in here,' Sandra interjects and moves her hand to her heart. 'For me it's all about love,' she says and emphasizes once again that it is all about feelings. It seems that this sense of pride and love that the students want to convey through their national symbols. 
It is hard not to notice such emphatic markers as large, colourful flags on a person's clothing. Attired in these, there won't be any doubt about what Zahra and Diana are, or rather how they want to be seen and interpreted: as proud of being associated with Iraq. It is according to Hall (1997) a way to visually consolidate their identities, a symbolic act that creates meaning and expresses affiliation through a discourse of national belonging. It is a way for the students to represent themselves where the representation involves the use of language, signs or images to say something meaningful about the world or people. By representation, we communicate meaningfully with others. But the meaning is dynamic, involving an active process of interpretation, and the viewer's interpretation is never exactly the same as what the wearer wishes to signal (Hall, 1997).

The visual symbols constitute a communicative process that does not necessarily include the spoken language. Although the youth, in some situations, talk about themselves as Swedes, they usually don't mark this affiliation by featuring the Swedish flag or a map of Sweden on their clothing. Due to their darker hair and skin they obviously look non-native and in order to avoid being forced into the position of belonging to a perceived homogenous group of 'immigrants' they must express their unique ethnic and national belongings, which is essential if these are to be affirmed. This expression does not mean that the youth do not perceive

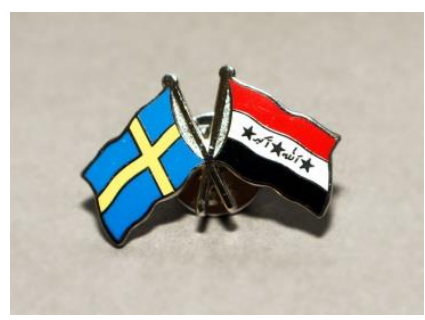


themselves as Swedes. Indeed on one occasion Sandra shows me a pin she has obtained featuring both the Iraqi and the Swedish flags (Figure 2). She explains that it fits her better because she is both Swedish and Iraqi.

Ethnic groups are defined in relation to other groups and appear through their boundaries, the boundaries being a social product of varying importance (Barth, 1969/1994, Eriksen, 1993/2007). Ethnicity is thus produced and maintained through social contact and by contrasts in relation to other groups. This contact and contrast is a prerequisite for ethnicity (Barth, 1969/1994, Eriksen, 1993/2007), and the main characteristic of communities as well as subgroups is the fact that they are exclusive not everyone can be part of a certain community or group. Ethnic communities also require a relationship to other groups in order to be constructed in ethnic or national terms. Through the symbols the students highlight similarities to some groups as well as differences to other groups (cf. Bucholtz, 2011: 57).

It is important to note that the symbols are apparently not used as a form of resistance or counter-culture, as commonly described in the youth culture field (cf. Johansson and Lalander, 2012). Instead, the symbols are used inclusively, to show off an aspect of a broader identity. The pin that is so highly valued by Sandra is a good illustration of the inclusiveness of the invoked national identities. By wearing the pin Sandra displays a local youth culture as well as her own active contribution to it in constructing these 
rather new mixed identities as Iraqi and Swedish and Chaldean ${ }^{1}$ (as Sandra one day equally proudly displays a Chaldean flag). This contrasts sharply to the exclusive, far right nationalist youth cultures that are currently re-emerging in Europe.

\section{Religious and national representation}

Jenkins (2007: 129) highlights the Danes extensive use of the Danish flag and the contradictory fact that it is for most of the time, if not actually invisible then simply part of the background (cf. Billig, 1995/2004). Despite its constant use people do not think of, and even less analyse it. When asked about the use of the flag both young people and adults responded that 'it's just how it is' and that they haven't really given the flag much thought (Jenkins, 2007). The banal nationalism (cf. Billig, 1995/2004) involved is simply part of the background.

The visual symbols used in this study are in contrast far from invisible, melted into the background, or simply reckoned as 'just how it is'. An interesting matter is the relation to the age of the carrier. During my yearlong fieldwork I never saw adults wearing these symbols; they all seemed to be part of a local youth culture; produced, purchased, painted, printed, or crafted by active choices among young people. Another significant difference is that there is not simply one flag, but multiples (alongside many other symbols). This might be the reason why they don't blend into the background; instead they are rather visible and eye-catching. 
To carry the symbols is an active and sometimes prolonged process. Diana knows that I was born in Syria, and she repeatedly asks me, and her schoolmates, if we or someone we know is about to go there. The reason is a bracelet, of a type that several schoolmates, including her classmate George, have bought in Syria. The bracelet contains icons: Christian religious images on brown wooden plates, threaded on an elastic cord interspaced with tiny wooden beads

(Figure 3).

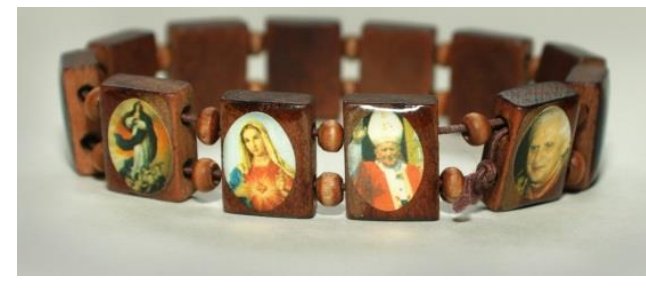

Figure 3

One day, as I come to school, Diana holds out her arm to me. Around her wrist is her long wished-for bracelet. Ahmed, the new sports teacher, who, like Diana, is from Iraq found it and gave it to her. Thus by talking about the bracelet, and informing everyone around her about her desire for it, Diana finally got it and was able to convey her religious affiliation nonverbally.

While Diana's bracelet was relatively inexpensive, many of the other symbols the students carried had significant economic value, as they were made of gold. Miles et al. (1998) claim that any consideration of the role of consumption in young people's lives needs to acknowledge the fact that although young people are concerned with practical factors and value for money, what is fashionable is similarly significant. 
The students claimed that they found the ornaments pretty, but this was not the main reason they carried them. When asked directly they answered tersely: 'because I am Muslim' or 'because I want to show that I am a Christian'. The symbols were thus active displays of a certain affiliation (cf. Miles et al. 1998). Such open displays are far from universally desirable. In her work on teenage school students in Northern Ireland Leonard (2006) describes their fear of verbal harassment or physical violence because of the ethnic, religious and political conflict between Catholics and Protestants. There are no physical differences between Catholics and Protestant, the school one attends, and its school uniform, instead becomes one of the highly visible emblems of religious identity (as children of different churches usually attend different schools). School uniforms were once introduced in Europe as a way to play down the children's economic backgrounds. Somewhat paradoxically in the context of Northern Ireland, the school uniform increases risks rather than serves as a safety measure for students (Leonard, 2006).

Unlike the students in Leonard's study, the students in this study did not fear to openly display their national, ethnic and religious affiliations by wearing ornaments and clothes with religious, ethnic or national markers and by drawing flags in their notebooks, files and folders. To my knowledge these symbols never resulted in physical violence. It seems that in Stockholm, such active identity display were not dangerous, although they could give rise to negative reactions, a fact the students were conscious of. 
When Esme, a girl who was widely recognized in school, and often at the centre of attention, one day arrives to school wearing a borrowed scarf featuring the Kurdish flag, she seems self-conscious and well aware that it will cause reactions. Esme is outspoken about her support for the $\mathrm{PKK}^{2}$ and strives, as well as some other students do, for an independent Kurdistan. The flag she carries then becomes a political statement provoking some schoolmates who fear that their countries of origin will lose territory. In wearing the scarf Esme therefore conveys a political message. The scarf interpellates viewers, to use Althusser's term (1971/2001). Her ethnic as well as political affiliations are consolidated visually and publicly, and the reactions are many and varied. Some quip at Esme as they usually do, by teasingly reminding her of the Kurdish peoples' lack of a territorial state. A scarf like that does not fade into the background. Some schoolmates with a Kurdish background want to know where she bought it so that they might obtain a similar one; others wonder whether they can get a similar scarf featuring another nation's flag.

When someone comments on Esme's scarf, they simultaneously confirm that they have seen it and understood what it represents. It is through other people's reactions that Esme and her identity is both made visible and confirmed as visible. Viewers are not passive recipients of a message but active agents in constructing meaning in the images they receive. The meaning is not inherent in the image; it is produced in a complex social interaction between the picture, the viewer and the context (Sturken and 
Cartwright, 2009:55, Hall, 1997: 24). Through references to flags, students construct both ethno-national and ethno-cultural belonging, and affiliate with their friendships network in school by learning about the symbolisms that their friends refer to (Schmitt, 2010: 173-174, cf. Hart, 2012).

\section{Establishing communities}

Diana, Zahra and Sandra are having lunch when a younger girl passes by their table. She is wearing a scarf and it is clear that it represents the Iraqi flag with its colours of red, white and black, green stars and Arabic script (Figure 4). She is immediately stopped by the girls. Zahra asks enthusiastically, almost ebulliently, where the girl has bought the scarf. The girl answers cheerfully that it was bought in Syria. Zahra looks a bit sceptical; she

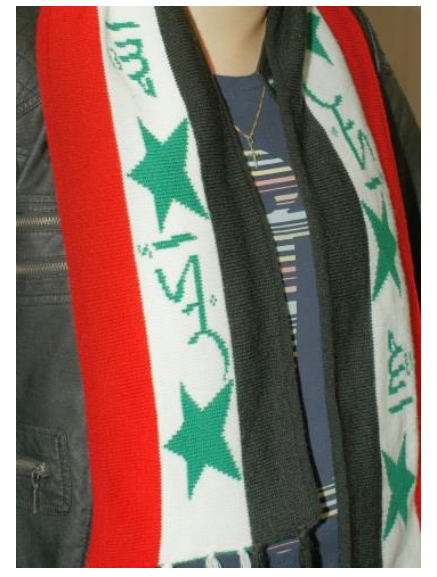

Figure 4 frowns and says in a serious tone: 'I was in Syria last summer and I didn't find any.' Sandra gently caresses the scarf and reads the Arabic script out loud: 'allah akbar' [God is greater]. Zahra looks even more impressed. She turns to her friends and says: 'next time someone I know is going, I'm gonna tell them to buy three' and then points to herself and her friends. A while later, the girl again passes by and Sandra amiably asks her if she can borrow her scarf. Only while they're having lunch, she hastens to add. The girl smiles, bunches the scarf into a ball and throws 
it to Sandra, who runs her hand gently over it and then solemnly wraps it around her shoulders.

She keeps caressing it where it hangs from her shoulders and the others look longingly at it. At that moment, their classmate Goran passes by on his way out and exclaims: 'ay, terrorist!' The girls immediately respond in an insulted way.

'What'd ya mean, terrorist?' Zahra yells out. 'It doesn't mean you're a terrorist because you love your country. And we're proud!' she finishes with a selfdefensive tone in her voice. By that time Goran has left and Zahra turns to us, adding in a serious tone: 'as if we'd dare bomb ourselves.' A moment later, Diana borrows the scarf; she puts it around her shoulders and runs her fingers gently through its fringes. At that moment Berit, the crafts teacher, walks by. Zahra asks her 'can we make things like this in craft'? Berit examines the scarf and says that it would be possible. Zahra wants to know what grade she will get if she makes such a scarf and when Berit answers 'MVG' (the best possible grade), Zahra lights up. 'I will make one, then I'll get an MVG', she nods happily. Before we leave the dining room, Diana returns the scarf to the owner and thanks her for lending it. On the way to the classroom, we meet a boy wearing the same scarf. The girls approach him all at once, while asking where he got it. He retreats a few steps, taken aback by their enthusiasm. He says that he bought it in Syria and it turns out that the girl in the lunch room is his sister. When I ask the girls if they knew the girl with the 
scarf, they shrug and inform me that she attends the school and that she's probably in the sixth grade.

Material things play an important part in youth's lives, not in and of themselves, but for the relationships and identities that can be established through the meaning endowed in them. The key word here, then, is communication. Communication enables youth to facilitate social participation and thereby construct a recognisable identity (Miles et al.1998). The symbols allow students to establish contact with unfamiliar peers and to get to know each other in a relaxed way. As the above case shows, the students position themselves as individuals, affiliated with a common nation through the symbolism negotiated in the scarf. They create a temporary community with an unknown student, a community bridging boundaries of age, religion and ethnicity (since Diana and Sandra call themselves Chaldeans). The symbols are highly visible markers of belonging and thus they are used to establish contact in ways that would not otherwise have been possible (cf. Widdicombe and Wooffitt, 1995: 163). But the same symbols that established a community also give rise to critical comments: in this case, Goran addresses them as potential terrorists ${ }^{3}$. The girls portray themselves as individuals with associations to Iraq, but at the same time risk being interpreted as something else. The meaning of national symbols is neither fixed nor eternal. It is the situation in combination with the agents' past experience that gives the symbol its value and meaning. Everyone does not interpret the same image in the same way, and the 
interpretation of an image can be the opposite of what the sender had in mind (Fox and Miller-Idriss 2008, Sturken and Cartwright, 2009: 75, Hall, 1997). For the girls' part, the scarf symbolizes pride in a group affiliation, but Goran interprets it in a different way. His accusation of terrorism alters the girls' reaction. They change from admiring the scarf to defending it. It does however not alter the girls' relationship to the scarf as it is loaded with other meanings. The girls challenge Goran's interpretation both verbally and when they shortly after his comment ask another schoolmate where he bought his scarf, hoping to obtain a similar one. The symbols are also used for another purpose, namely to stage the good student who asks her teacher to produce a desired item of clothing in the context of craft education and obtain a good grade. The girls are obviously not put off by Goran's reaction to the scarf, they still desire it, and during the school year, they will acquire additional artefacts featuring visuals symbols that mark national, ethnic and religious affiliations. One possible interpretation is that they find mutual support in being many individuals at school that share affiliations to Iraq.

\section{Border work}

While it is possible to create oneself through visual means, one has to realize that these means also have their limits (Hall, 1997:31). Eriksen (1993/2007: 44) argues that while ethnicity can be significantly affected by the actors themselves, the lengths to which one can push one's ethnic identity are not limitless. 
During an English class, the teacher, Maili, informs the class about upcoming graded reviews on Friday. At that point, Sercan reminds Maili that he will not be attending classes on Friday because it is Bayram, an annual Muslim religious celebration, and he, as well as some other Muslim students, have gotten the day off. When George hears Sercan explain his absence, he hastens to say that he, too, will celebrate Bayram. George, who usually calls himself Christian, looks around the classroom and smirks at his friends. Maili glances at George, nods and mumbles a distracted 'ok'. George's upstaging of his mates at having tricked the teacher and thus having escaped Friday's lesson is however short lived. His classmate Sercan immediately reveals that George is not a Muslim. Maili throws George a questioning look and he hastens to reply that he is at least 'half' [Muslim], pursuing this as a legitimate reason to get some time off to celebrate. But Sercan points to George's bracelet with icon images, and remarks that he actually is a Christian. Thus George has to attend his English lesson.

George draws on a belonging that for the time being would provide him with certain privileges, in this case to escape the impending review. Sercan understands that George does not intend to convert to Islam, but employs it temporarily for a personal gain. Sercan picks up on this, and from his comments we get his message that religion is not something that can be acquired and discarded at leisure. The icon bracelet finally foists George's attempts to pass as a Muslim, or even as 'half' Muslim. Unlike Maili, Sercan is able to instantly point to the bracelet as a marker of George's religious affiliation. 
This episode stresses that the wearing of specific symbols is not open to everybody - if everyone wore similar symbols, they would lose some of their meaning.

When Ninve, who was born in Iraq, one day noisily skitters into the cafeteria, wearing a borrowed black sweatshirt featuring a large Chilean flag on the back, she is immediately reproached by the other Iraqi students present. 'You wouldn't believe that she's from Babylon,' Diana says disappointedly. 'You'd think she's from Chile,' she adds, shaking her head.

Borrowing symbols to which one does not have personal ties is far from unproblematic (cf. Bucholtz 2011). Far from blending into the background, they are at the forefront of the students' visual identity (cf. Billig, 1995/2004, Jenkins, 2007). Wearing the 'wrong' symbol attracts immediate negative attention. This is also the reason why Zahra does not include me when she talks about purchasing three scarves in the colours of the Iraqi flag. This indicates that the students are not primarily trying to construct identities as non-Swedes and it indicates a lack of contradiction between majority and minority identities. Instead, the point of contention lies between different minority groups. For instance, wearing or sporting a national symbol to which you have no ethnic link is considered problematic. Entitlement is a major issue. It could however be noted that as the local minority identities are inclusive of the Swedish majority identity, they are in a way all linked, both in their mixed Swedishness and in their positions as minorities. 
Thus while the students do challenge each other, it is impossible for them to be wholly exclusive the way right-wing nationalist are.

\section{Symbols as conversation starters}

The symbols create touching points for conversations, enabling dialogue that would otherwise not have taken place. Zahra one day points to Diana's home-made bracelets and informs me that the colours are meant to symbolize the Iraqi flag. I nod and inform her that it might as well be the Syrian flag since the two countries have similar flags. The conversation that follows becomes a way to liven up the everyday boredom in school with some entertainment and personal flair.

Zahra: Like, you have two stars, we have three. You've nicked one from us! [Giggles]

Diana: $A B O O$ [slang: Wow]! [Laughs challengingly]

Layal: So you had four?

Zahra: No, we had three!

Layal: But how can we ...

Zahra: No, I'm just kidding.

Diana: It's you who have nicked it from us!

Zahra: Yeh, you have!

Diana: You had before, it was green up, then black, and green stars and white.

Your old one was like that! 
Layal: How do you know $?^{4}$

Zahra: Because she has seen it, she is an expert on these matters [in standard Swedish].

Diana: Yours was this [draws in her notebook], it was çok [Turkish: very] ugly. It was green and then red stars.

Zahra: Then they looked ours, they just: 'come, let us imitate them!'

Alexandra: What are you talking about?

Diana: The flag! [Evasively. Diana and Zahra laugh loudly]

The accusation would not have been as entertaining without someone 'representing' the other, in this case Syria in the conversation. It also requires that Diana and Zahra align with each other on the basis of their affiliation with Iraq. It is important to note that Diana and Zahra take turns to accuse Syria, or perhaps me as the representative of Syria, of stealing ideas for the Syrian flag, but that they do it in a friendly tone and with a twinkle in their eye. Despite the accusation, they include me in the conversation and in their community. They seek eye contact with me and wait for my reactions and responses. But when Alexandra, who has no connection to Syria or Iraq, attempts to enter the conversation by gently wondering what we're talking about, Diana's response, is short and evasive. No one bothers to explain to her what the conversations concerns and there is no possibility for Alexandra, who is not included in the 'accusation', to be included in the conversation. 
Symbols enable students, and sometimes teachers, to approach important issues. Diana, Sandra, Zahra and Alexandra are working with a group assignment when Osman, their social science teacher, approaches them. He notices Diana's gold pendant (figure 1) and questions the combination of the nation of Iraq with the Christian cross. In a natural way the girls, as well as Osman, all reveal their religious affiliations. The conversation turns to the conflict between Shiite and Sunni Muslims in Iraq.

Osman: But don't you think it odd that they have the same faith still some hate each other?

Zahra: Mm ...

Diana: That's it! [the problem]

Osman: What do you think causes it?

Zahra: We hate no one!

Diana: Maybe not you, but there are those who do!

Osman: Yeah, because there's a bit of politics involved as well. Religion has always been used for, what you say, political gains. So, I mean, I'm a politician, I want the power; I come and say things that you like: 'all Shiites shall have ten more mosques.'

Zahra: Yes, Walla! [Arabic: I swear]

Osman: They will have electricity in their villages, they will have water and I will do all this so that people will listen to me and then I talk shit about the poor 
Christians. 'They destroy our country' and so on. Like, I play to your emotions, you know? What for? For me to gain the power. You get me?

Zahra: Yah, I get you [sighs].

Osman: That's what's happening in the world.

Zahra: In Iraq, huh?

Osman: Especially in Iraq, cause Iraq is a special area because it is, there is a Kurdish area, a Sunni area and mixed areas, there are Turkmen, there are Assyrians, there are Christians, there are Chal...

Sandra: Chaldeans!

Osman: Chaldeans!

Zahra: Kurds! Arabs!

Osman: Like, both religion and nationality, it is against each other. Some countries talk about nationalism, as we will learn, we will talk about ideologies. This is the easiest way to fool people. Religion is one, nationalism is the other. For example, in Denmark there was a party founded. It became the second biggest party. You know why, from nothing they got this big?

Zahra: Why?

Alexandra: They talked shit about Muslims.

Osman: They talked shit about Muslims. They talked shit about immigrants, especially about Muslims, in Denmark. That all the misery is due to the Muslims. 
Diana's pendant gave rise to this conversation, a conversation that continued well after the excerpt's end. Through the conversation, we learn what different religious and ethnic affiliations are represented in the group. The pendant then leads to an unexpected bonus, as it leads to an opening to talk about history, ideology, politics, power, immigration policy, psychology, and moral issues. Osman is covertly giving his students a lesson in social science. However, it is not a traditional lesson; it was both unplanned and unstructured. Osman also involves his student in the conversation by asking questions and it is a discussion that touches and engages the students, because he is using Iraq, whose map Diana is literary carrying close to her heart to illustrate his points.

\section{Conclusion}

The symbols the students use seem to have an important role in providing the day-today framework by which they construct themselves among their peers carry distinct messages embedded with positions the students wish to take. The symbols convey associations in a way that is both communicative and nonverbal, thereby allowing students to create stories about themselves through their use of images which they give symbolic meanings and values. This is a very convenient way to reach a multitude of viewers with a message. In this way, the students produce and reproduce the nation in their everyday lives. 
The symbols create opportunities for the students to establish contacts across barriers of age, gender, religion and ethnicity. They make the students talk both to and about each other and this allows the symbols to act as conversation starters about important topics: Zahra combines her use of symbols with crafts class as a way to get good grades and the teacher Osman captures the students' interest in Diana's symbol in order to further their education. The symbols form communities, but like all communities, these are also exclusive. Above all, the symbols show that the students are proud of their associations and wish to convey them visually, openly and publically.

The body of research on youth culture states that youth are highly engaged in constructing group affiliations and identities. For the students depicted in this article, the emphasis lies on the complexity and plural multitude of these identity formations in an inclusive and non-aggressive form. The goal lies not in provoking or doing resistance, but rather in a romantic search for origin and uniqueness. Far from being a matter of counterculture or a way of resisting parents or mainstream society, the symbols link the youth to their parental origins as well as to the Swedish society. 


\section{References:}

Ackroyd, J. and Pilkington, A. (1999) Childhood and the construction of ethnic identities in a global age: A dramatic encounter. Childhood 6 (4) 443-454.

Althusser, L. (1971/2001) Lenin and philosophy and other essays. New York: Monthly Review Press.

Anderson, B. (1983/2003) Imagined communities. London, New York: Verso.

Barth, F. (1969/1994) "Introduction”. I Barth Fredrik (red) Ethnic groups and boundaries: the social organization of culture difference. Oslo: Pensumtjeneste.

Billig, M. (1995/2004) Banal nationalism. London: Sage.

Bucholtz, M. (2011). White kids: Language, race, and styles of youth identity. Cambridge: Cambridge University Press

Eriksen, T. H. (1993/2007) Ethnicity and nationalism: anthropological perspectives. London: Pluto Press.

Eriksen, T. H. (2010) Small places - large issues: An introduction to social and cultural anthropology. New York: Pluto Press

Fox, J., E. and Miller-Idriss, C. (2008) Everyday nationhood. Ethnicities 8 (4) 536-576 
Geertz, C. (1973) Ideology as a cultural system. In The interpretation of cultures, pp. 193-229. New York: Basic Books.

Hall, S. (1997) The work of representation. In Hall, Stuart (ed) Representation: cultural representation and signifying practices. London: Sage Publications.

Hart, J. (2002) Children and nationalism in a Palestinian refugee camp in Jordan. Childhood 9 (1): 35-47.

Hobsbawm, E. J. (1991) Nations and nationalism since 1780: programme, myth, reality. Cambridge: Cambridge University Press

Jenkins, R. (2007) Inarticulate speech of the heart: Nation, flag and emotion in Denmark. In Eriksen, T. H. and Jenkins, R. Flag, nation and symbolism in Europe and America. New York: Routledge.

Johansson, T. and Lalander, P (2012) Doing resistance - youth and changing theories of resistance. Journal of Youth Studies. 15 (8): 1078-1088.

Leonard, M. (2006) Segregated schools in segregated societies: Issues of safety and risk. Childhood 13 (4): 441-458.

Miles, S., Cliff, D and Burr, V. (1998) Fitting in and sticking out: Consumption, consumer meaning and the construction of young people's identities. Journal of Youth Studies 1 (1) 81-96. 
Miller-Idriss, C. and Rothenberg, B. (2012) Ambivalence, shame and pride:

conceptualisations of German nationhood. Nations and Nationalism. 18 (1) 132-155.

Yuval-Davis, N. (2006) Intersectionality and feminist Politics. European Journal of

Women's Studies. 13 (3): 193-209.

Schmitt, I. (2010) "Normally I should belong to the others": Young peoples gendered transcultural competences in creating belonging in Germany and Canada. Childhood. 17 (2): 163-180.

Sturken, M. and Cartwright, L. (2009) Practices of looking: An introduction to visual culture. New York: Oxford University Press.

Widdicombe, S. and Wooffitt, R. (1995) The language of youth subcultures: Social identity in action. New York: Harvester Wheatsheaf.

\footnotetext{
${ }^{1}$ Chaldeans are a Christian, ethnic group who speak a variant of Armenian. The group originates from Iraq, Iran, Turkey, Syria and Lebanon.

${ }^{2}$ The Kurdish worker's party commonly known as PKK and their struggle for an autonomous Kurdistan.

${ }^{3}$ This statement is dated autumn 2007 when a series of suicide bombings shook Iraq - events that featured prominently in the Swedish media.

${ }^{4}$ Here I must also admit that I am not well informed. When I later investigate further I learned that both the Syrian and the Iraqi flag have changed appearance many times and at times they even had the same flag in a common union.
} 